\title{
Field-based radiotherapy using volumetric modulated arc therapy (VMAT) for skin field cancerisation (SFC)-outcomes from 100 consecutive fields
}

\begin{abstract}
Introduction: Skin field cancerisation ( $\mathrm{SFC}$ ) arises from prolonged sun exposure and increases with age, especially in fair skinned individuals. Multiple areas of the skin can be involved, resulting in poor quality of life and cosmesis. Invasive skin cancer can arise causing morbidity and even death. The long-term efficacy of traditional treatments is disappointing. Volumetric modulated arc therapy (VMAT) allows efficient definitive radiotherapy treatment of large convex skin fields. This retrospective, single-institution study presents a case series of 100 consecutive SFC fields in 74 patients.
\end{abstract}

Methods: The first 100 fields treated with VMAT for SFC by the same clinician (GBF) were identified through departmental medical records. Patient, field, treatment, and outcome factors were collected for analysis. The date of the first consultation was collected to calculate the rate of referrals over time.

Results: The first patient completed treatment in October 2013 and the last patient in May 2020. Seventy-four mostly male (84\%) patients with a median age of 76 years were identified. At least $75 \%$ had previously undergone treatment for SFC and $11 \%$ were immunosuppressed. Twenty percent of patients had more than one field treated with VMAT. Ninety-three fields of keratinocytic lineage were found with most involving the legs (27), scalp (23) or nose (20). Average planning target volume (PTV) size was 175 (range 5 $1282) \mathrm{cm}^{3}$. Average prescribed dose was 50 (range $15-72$ ) Gy, average delivered dose was 45 (range 4 - 72) Gy. Sixty-four (69\%) of fields completed the prescribed course. There were $15(16 \%)$ in-field recurrences. In-field control on an intention-to-treat basis was $89 \%$ at 12 months. For those who completed the prescribed treatment, in-field control at 12 months was $98 \%$ as compared with $71 \%$ for those who did not $(\mathrm{p}<.0001)$. PTV size did not impact treatment completion. In those who completed the prescribed treatment, recurrence was not associated with PTV size nor dose. The rate of referrals increased over time.

Conclusion: VMAT for SFC is feasible and effective if the whole course is completed. These findings support our national protocol. More research is warranted to predict radiosensitivity so that treatment can be better tailored. Research to identify patients at risk of lower leg lymphoedema before they become symptomatic is also needed to ensure treatment completion thereby reducing the risk of recurrence.

Keywords: skin neoplasms, radiotherapy, actinic keratosis, Bowen's disease, in situ squamous cell carcinoma, basal cell carcinoma, intraepithelial carcinoma, lentigo maligna, melanoma, volumetric modulated arc therapy, intensity modulated radiotherapy, case series, nose, scalp, leg, arm, forehead, back, skin field cancerisation
Volume 8 Issue I - 202 I

\author{
Gerald B. Fogarty,' Susan Young,' Serigne \\ Lo, ${ }^{2}$ James O'Toole,' Mark Wanklyn,' David \\ Wong, ${ }^{3}$ Susan Sinclair, ${ }^{3}$ Gavin Gottschalk, ${ }^{4}$ \\ Pascale Guitera, ${ }^{5}$ Stephen Shumack ${ }^{6}$ \\ 'GenesisCare, Mater Hospital, Australia \\ ${ }^{2}$ Melanoma Institute Australia, Australia \\ ${ }^{3}$ Eastern Suburbs Dermatology, Australia \\ ${ }^{4}$ Chatswood Dermatology Centre, Australia \\ ${ }^{5}$ Dermatology, Melanoma Institute Australia, Australia \\ ${ }^{6}$ Central Sydney Dermatology, Australia
}

Correspondence: Prof Gerald Fogarty, Radiation Oncology, Mater Sydney, Crows Nest, NSW Australia, Ph +6I 294588050 , Fax+61 29929 2687, Email Gerald.fogarty@genesiscare.com

Received: March 05, 2021 | Published: March 19, 2021
Abbreviations: SFC, skin field cancerisation; VMAT, volumetric modulated arc therapy; PTV, planning target volume; SFC, Skin field cancerisation; IEC, intraepithelial carcinoma; BCC, basal cell carcinoma; cSCC, cutaneous squamous cell carcinoma; RCT, randomised controlled trials

\section{Introduction}

Skin field cancerisation (SFC) describes areas of sun-exposed skin with confluent microscopic and macroscopic in-situ disease. This phenomenon is described by different names. In-situ disease from keratinocytic precursors can be described as in-situ cutaneous squamous cell carcinoma, Bowen's disease or intraepithelial carcinoma (IEC). These fields are prone to developing invasive malignancy such as basal cell carcinoma (BCC) and cutaneous squamous cell carcinoma (cSCC). ${ }^{1}$ In-situ disease from melanocytic precursors can be described as in-situ melanoma, lentigo maligna or Hutchinson's melanotic freckle (HMF). These fields are prone to developing invasive malignancy such as lentigo maligna melanoma. ${ }^{2}$ These fields occur especially in older fair-skinned patients with Fitzpatrick skin type 1 and $2^{3,4}$ after a lifetime of sun exposure. The incidence increases with age, ${ }^{5}$ particularly in the immunosuppressed. ${ }^{6}$ Patients can suffer from invasive malignancy but also from poor quality of life from SFC itself with pruritus, flaking hyperkeratotic skin and poor cosmesis. ${ }^{7}$

Treating the whole field can prevent further issues. Fields can be extensive (ESFC), involving over 50 square centimetres $(\mathrm{cm}),{ }^{8}$ which makes surgery difficult, especially in functionally and cosmetically sensitive areas. This patient cohort may already have significant 
comorbidities, creating further surgical challenges. The durability of traditional non-surgical field treatments is disappointing., ${ }^{9,10,11}$ The problem is increasing on a worldwide scale, particularly in Australia. ${ }^{12,13}$

Volumetric modulated arc therapy (VMAT), ${ }^{14-19}$ allows efficient definitive radiotherapy (RT) of convex SFC, such as over the nose, and also of ESFC commonly found over sun exposed scalps, foreheads, torsos, forearms, backs and legs (Figure 1). VMAT can treat large, long, yet thin convex shaped targets, as found in ESFC, with excellent conformality and homogeneity of dose and rapid fall off, and is superior to a brachytherapy moulds, matching electron fields or intensity modulated radiotherapy. ${ }^{14}$ Macroscopic invasive disease within these fields that may require more dose can be treated with a simultaneous boost technique (SIB) with VMAT. ${ }^{15}$

This study is a retrospective audit of the outcomes and experiences of the first one hundred consecutive fields treated with VMAT for SFC by one clinician $(\mathrm{GBF})$.

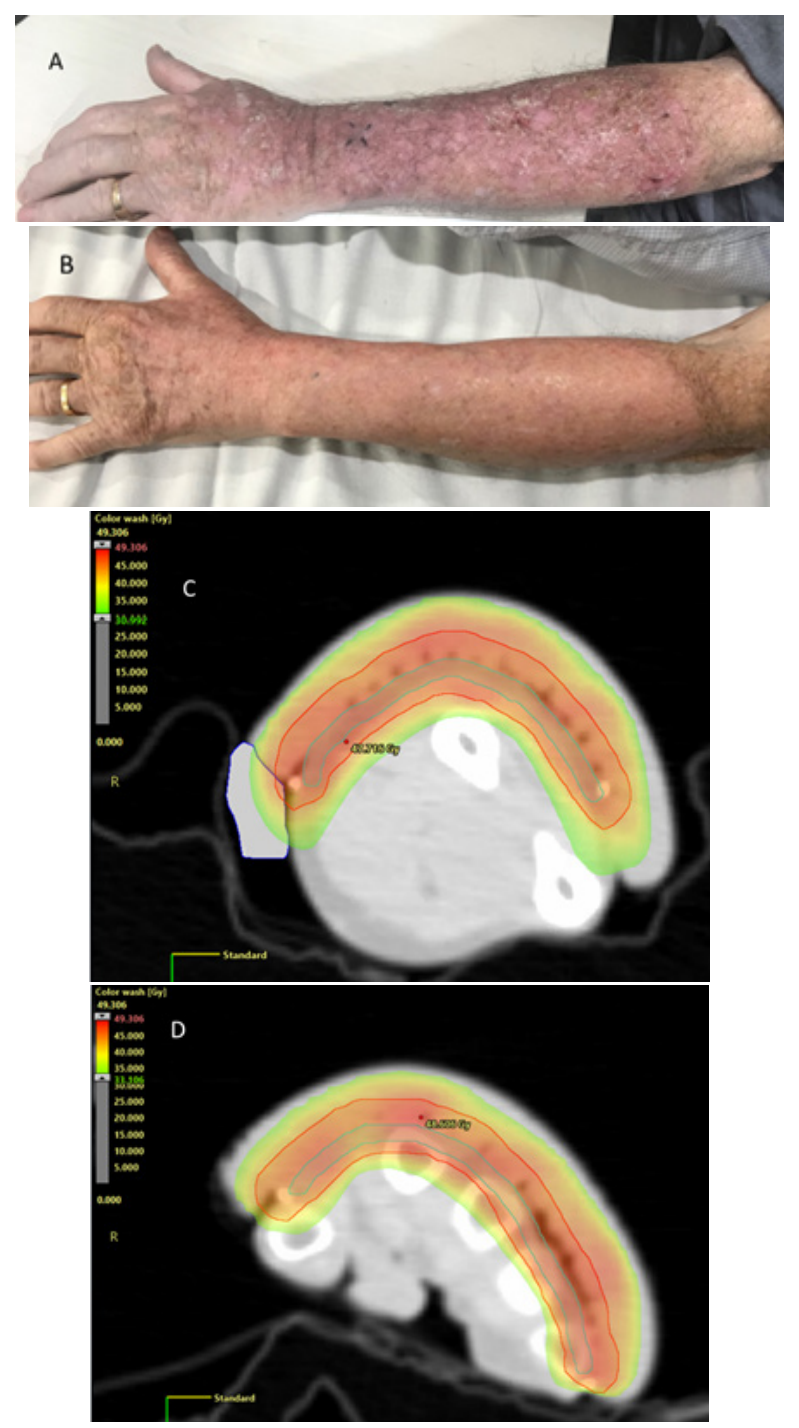

Figure I

A. ESFC on left arm at presentation

B. Post VMAT showing resolution of ESFC

C.Axial dosimetry of VMAT at mid arm level showing conformal and homogeneous dose encompassing a convex target

D. Axial dosimetry of VMAT at level of hand showing the same as C.

\section{Methods}

The cohort is the first one hundred fields treated by one specialised skin radiation oncologist over three GenesisCare radiation oncology centres in Sydney. It was part of an initial patient population used to determine the appropriate dose and volume of RT for in-situ skin disease for the still evolving GenesisCare national protocol. ${ }^{17}$ Patient consent to use de-identifed data for research purposes was prospectively collected. Data on consecutive cases of SFC treated with VMAT were sourced from departmental medical records. Patient, field, treatment, and outcome factors were collected for analysis. Treatment was delivered according to our national protocol ${ }^{17}$ which was evolving at that time.

\section{Patient factors}

Patient factors included age, sex, date of first consultation, relevant cancer comorbidities and, if relevant, the duration and means of immunosuppression. Additional patient factors were any previous solid cancer diagnoses and tumour type, and the number and type of any previous skin cancer or field therapies. Patients who had more than one field treated with VMAT were also recorded from the medical records.

\section{Field factors}

Field factors collected included the location of the field (scalp, face, nose, torso, forearms or lower legs), and the histology of the field(s), that is, whether they were of melanotic or keratinocytic lineage.

\section{Treatment factors}

Treatment factors included the intent of treatment. Intent was either radical for cure, or palliative for symptom relief. Other collected treatment factors included the total dose of radiation prescribed versus the total dose delivered. In terms of the volume treated, our published national protocol ${ }^{17}$ encourages a PTV measuring in depth from 10 to 12 millimetres $(\mathrm{mm})$. The area of field treatment in square centimetres $\left(\mathrm{cm}^{2}\right)$ was assumed to be approximately represented by the planning target volume (PTV), ${ }^{19}$ which was measured in cubic centimetres $\left(\mathrm{cm}^{3}\right)$. Whether treatment had been completed or not as per the initial prescription was also collected together with any reasons why there was a discrepancy.

\section{Outcomes data}

Outcomes data included the presence or not of a recurrence by the date of the last follow up (FU). Recurrence was mainly determined clinically upon physical examination by the radiation oncologist (RO), but biopsies were sometimes performed for pathological confirmation. The duration of FU was measured from the start of RT to the last FU. Persistent disease was included as a recurrence for analysis purposes. Data on the outcomes of those with invasive disease in the fields was also collected. These data were tabulated in an excel spreadsheet for analysis.

\section{Analysis}

Only in-situ fields of keratinocytic lineage treated with radical intent were included in the outcome analysis. This analysis studied factors that may be associated with recurrence. Melanoma and cases treated with palliative intent were not included in the outcome analysis and were tabulated separately.

All statistical analyses were carried out using $\mathrm{R}$ version 4.0.3 (R core Team, Vienna, Austria). For the entire keratinocytic lineage cohort treated with radical intent, recurrence over time was analysed 
for the whole cohort, followed by the whole cohort divided into anatomical field location, and then for the whole cohort divided into whether the treated field was on the head/neck/trunk as opposed to the limbs. This whole patient cohort was also assessed for recurrence based on immunosuppression status. The relationship of recurrence for the whole cohort based on whether the size of PTV ${ }^{19}$ was above or below the median PTV size was also calculated.

An analysis of the keratinocytic lineage cohort treated with radical intent was then performed. All patients had to have completed the prescribed treatment. The relationship of recurrence to the size of the PTV, whether above or below the median PTV size, was calculated. The relationship of recurrence to the total dose to field being above or below the median total dose was also calculated.

Individual patient data on the cohort that had recurrence and on the cohort that had invasive disease within the in-situ field at presentation was collected and tabulated. Individual patient data on the cohort treated for melanoma was also collected and tabulated along with cases treated with palliative intent.

\section{Results}

The first patient completed treatment in October 2013 and the las patient in May 2020.

Patient and tumour characteristics are summarised in Tables 1 and 2. Other results data is summarised in Tables 3-7 and Figures 2-10.

Table I Patient and field characteristics

\begin{tabular}{ll}
\hline Variable & $\mathbf{( N = 7 4 )}$ \\
\hline Age (years) & $76.2(37.0,96.1)$ \\
Median (range) & \\
Sex & $12(16.2 \%)$ \\
Female & $62(83.8 \%)$ \\
Male & \\
Previous skin cancer therapies & $45(60.8 \%)$ \\
Surgery & $7(9.5 \%)$ \\
Cryotherapy & $3(4.1 \%)$ \\
SXRT & $15(20.3 \%)$ \\
5 -fluorouracil & $4(5.4 \%)$ \\
PDT & $5(6.8 \%)$ \\
Methyl aminolevulinate & $17(23.0 \%)$ \\
None & $5(6.8 \%)$ \\
Unknown & $1(1.4 \%)$ \\
Number of fields treated & \\
\hline & \\
\hline
\end{tabular}

Abbreviations: N, number;SXRT, superficial radiation therapy; 5-fluorouracil, topical 5-fluorouracil; PDT, photodynamic therapy; methyl aminolevulinate, methyl aminolevulinate cream
Table 2 Patient relevant past history characteristics

\begin{tabular}{|c|c|}
\hline Patient Factor & Text \\
\hline \multirow{9}{*}{$\begin{array}{l}\text { Immunosuppressed how: } \\
\text { how long }\end{array}$} & $N=8$ \\
\hline & $\begin{array}{l}\text { Systemic lupus erythematosus: } 28 \\
\text { years }\end{array}$ \\
\hline & Polymyalgia rheumatica: 8 years \\
\hline & Polycythaemia rubra vera: $10+$ years \\
\hline & Heart transplant: 29 years \\
\hline & Rheumatoid arthritis: 19 years \\
\hline & Ulcerative colitis, infliximab: $10+$ years \\
\hline & Heart transplant: 19 years \\
\hline & Bilateral lung transplant: 20 years \\
\hline \multirow{3}{*}{$\begin{array}{l}\text { Previous solid cancer } \\
\text { diagnosis and what type }\end{array}$} & Prostate cancer: 7 years \\
\hline & Melanoma: 4 years \\
\hline & Bowel cancer: 2 years \\
\hline Melanoma & $\begin{array}{l}\mathrm{N}=6 \text { of which } 5 \text { were lentigo } \\
\text { maligna - all were not included in the } \\
\text { outcome analysis }\end{array}$ \\
\hline Palliative intent & $\begin{array}{l}\mathrm{N}=2 \text { (I was melanoma) - both not } \\
\text { included in the outcome analysis }\end{array}$ \\
\hline For outcomes analysis & $\begin{array}{l}\mathrm{N}=93 \text { in-situ disease of keratinocytic } \\
\text { lineage treated with radical intent - all } \\
\text { included in outcomes analysis }\end{array}$ \\
\hline
\end{tabular}

Abbreviations: $\mathrm{N}$, number

Table 3 VMAT fields per anatomical location and histology

\begin{tabular}{llll}
\hline $\begin{array}{l}\text { Anatomical } \\
\text { Location }\end{array}$ & In-situ disease & Melanoma & Total \\
\hline Scalp & $23(+ \text { I palliative })^{*}$ & 4 & 28 \\
Face & 8 & 0 & 8 \\
Nose & 20 & 2 & 22 \\
Torso & 6 & 0 & 6 \\
Arms & 9 & 0 & 9 \\
Legs & 27 & 0 & 27 \\
Total & 93 radical; I palliatively* & $6 * *$ & 100 \\
\hline
\end{tabular}

*I pt treated palliatively; $* * 5$ were lentigo maligna 
Table 4 Radiotherapy treatment details for those with keratinocytic lineage in-situ disease treated with radical intent ( $N=93)$

\begin{tabular}{|c|c|c|c|c|c|c|}
\hline $\begin{array}{l}\text { Anatomical } \\
\text { Location }\end{array}$ & $\begin{array}{l}\text { Number } \\
\text { of fields } \\
\text { *from above } \\
\text { table }\end{array}$ & $\begin{array}{l}\text { PTV volumes } \\
\left(\mathrm{cm}^{3}\right) \text { median } \\
\text { (plus range) }\end{array}$ & $\begin{array}{l}\text { Total dose } \\
\text { prescribed to } \\
\text { field (Gy) median } \\
\text { (plus range) }\end{array}$ & $\begin{array}{l}\text { Total dose } \\
\text { delivered to field } \\
\text { (Gy median (plus } \\
\text { range) }\end{array}$ & $\begin{array}{l}\text { No and } \% \text { of fields that } \\
\text { completed treatment } \\
\text { prescription }\end{array}$ & $\begin{array}{l}\text { No of in- field } \\
\text { recurrences } \\
\text { until last FU }\end{array}$ \\
\hline Scalp & 23 & $215(108,390)$ & $55(45,72)$ & $52(4,72)$ & 18 (78\%) & 5 (22\%) \\
\hline Face & 8 & $81.5(5 \mathrm{I}, 154)$ & $47.5(25,55)$ & $42(25,55)$ & $5(63 \%)$ & $0(0 \%)$ \\
\hline Nose & 20 & $2 \mid(5,162)$ & $55(15,60)$ & $50.6(15,60)$ & $16(80 \%)$ & $0(0 \%)$ \\
\hline Torso & 6 & $374.5(62,1282)$ & $45(25,55)$ & $37.3(25,45)$ & $4(67 \%)$ & $0(0 \%)$ \\
\hline Arms & 9 & $24 I(80,70 I)$ & $45(30,55)$ & $45(30,55)$ & $9(100 \%)$ & $0(0 \%)$ \\
\hline Legs & 27 & $467(31,944)$ & $45(27,65)$ & $34.2(16.2,65)$ & $12(44 \%)$ & 10 (37\%) \\
\hline Totals & 93 & $195(5,1282)$ & $50(15,72)$ & $45(4,72)$ & 64 (69\%) & 15 (16\%) \\
\hline
\end{tabular}

Abbreviations: PTV, planning target volume; Gy, Gray; No, number; Pt, patient; $\mathrm{cm}^{3}$, cubic centimetres; \%, percentage

Analysis for the whole cohort with keratinocytic lineage fields treated with radical intent $(\mathrm{N}=93)$

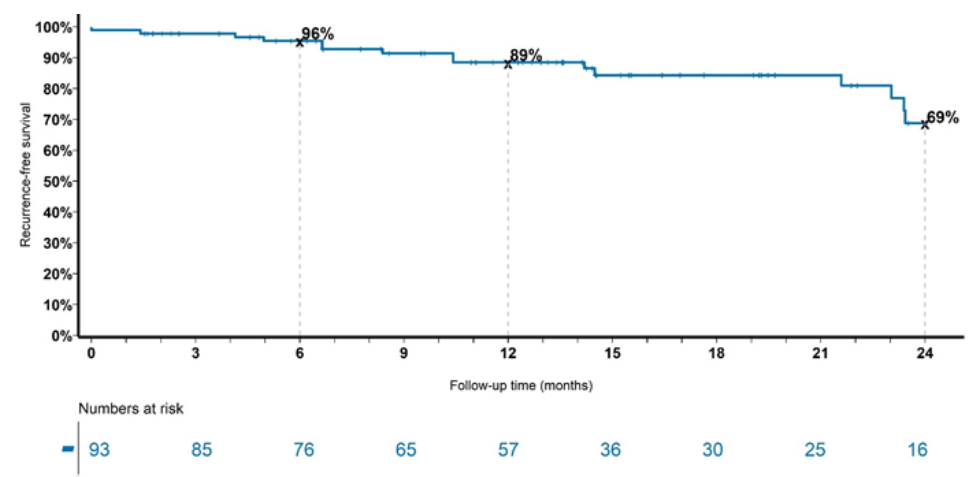

Figure 2 Recurrence over time for the whole cohort with keratinocytic lineage treated with radical intent. Note in-field control of $89 \%$ at 12 months.

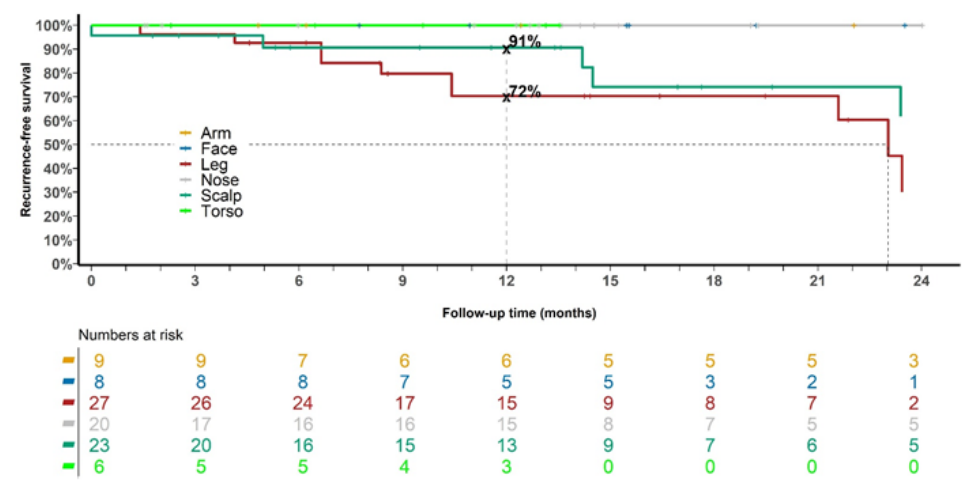

Figure 3 Recurrence over time for the whole cohort with keratinocytic lineage treated with radical intent divided into anatomical locations of scalp, face, nose, torso, arms and legs.

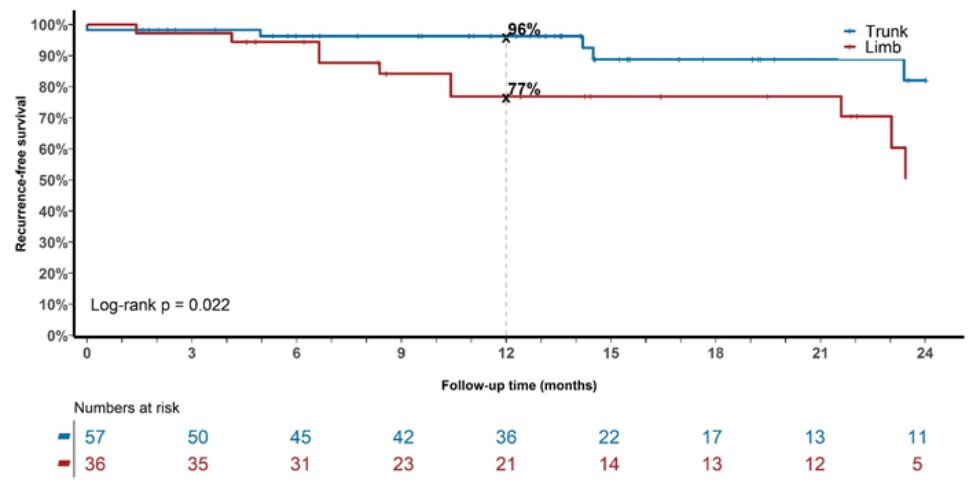

Figure 4 Recurrence over time for the whole cohort with keratinocytic lineage treated with radical intent divided into either trunk (scalp, face, nose, torso) or limbs (arms, legs). 


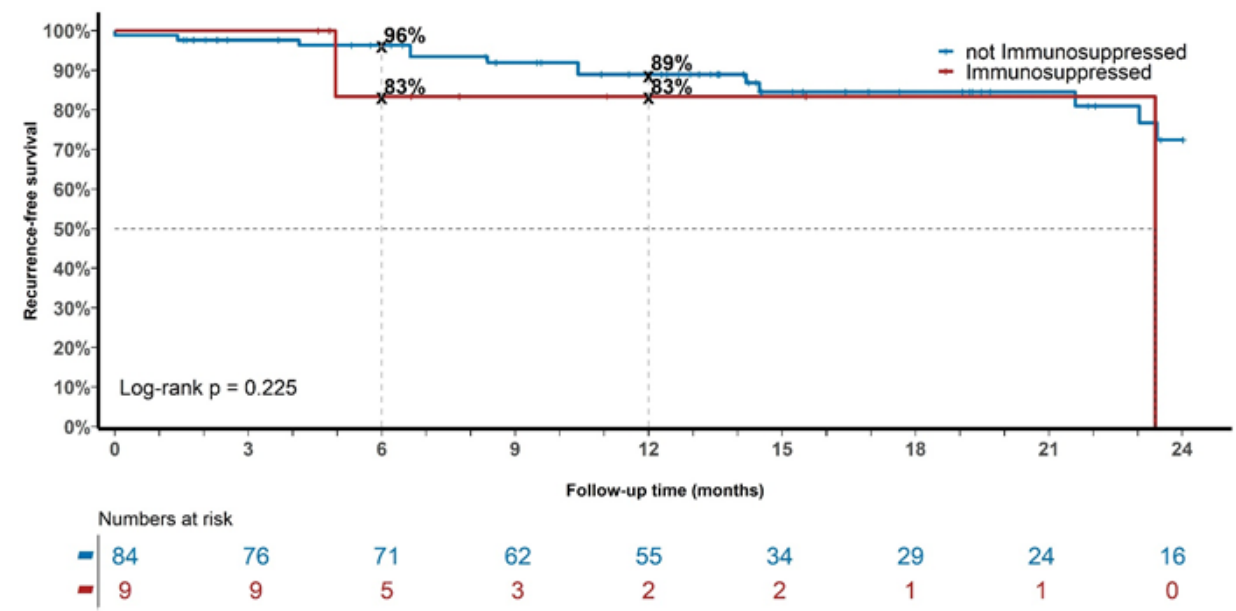

Figure 5 Recurrence over time for the whole cohort with keratinocytic lineage treated with radical intent divided into either immunosuppressed versus nonimmunosuppressed.

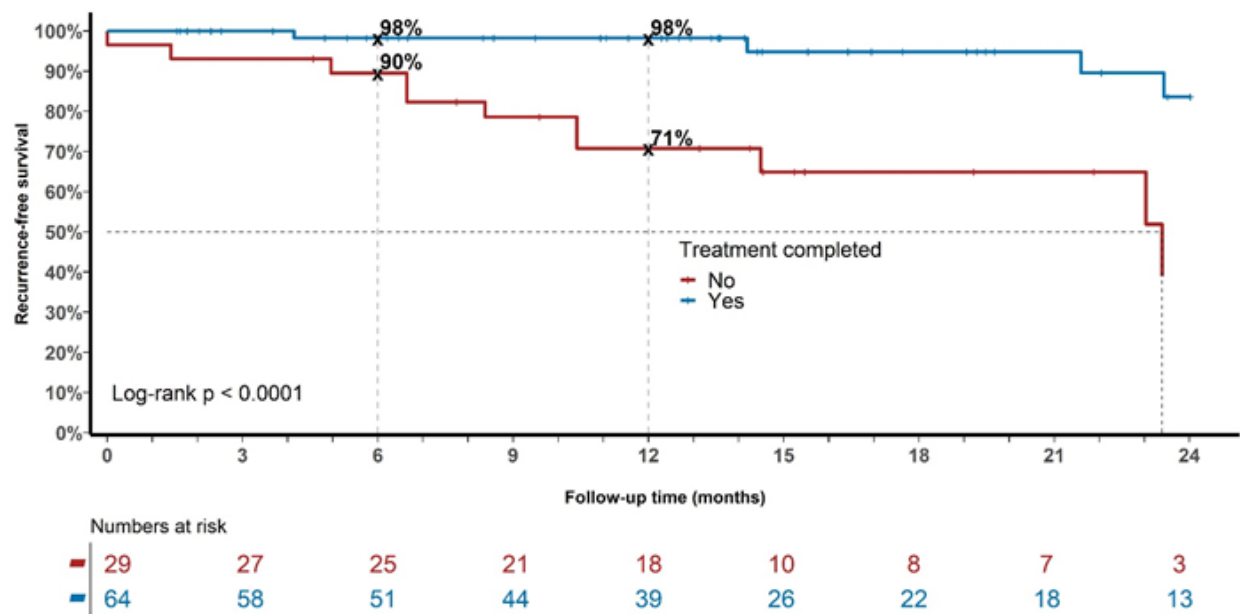

Figure 6 Recurrence over time for the whole cohort with keratinocytic lineage treated with radical intent divided into those who completed treatment versus those who did not. Note in-field control at 6 and 12 months of $98 \%$ for those who completed the prescribed treatment versus $90 \%$ and $71 \%$ respectively for those who did not (Log-rank p <.000I).

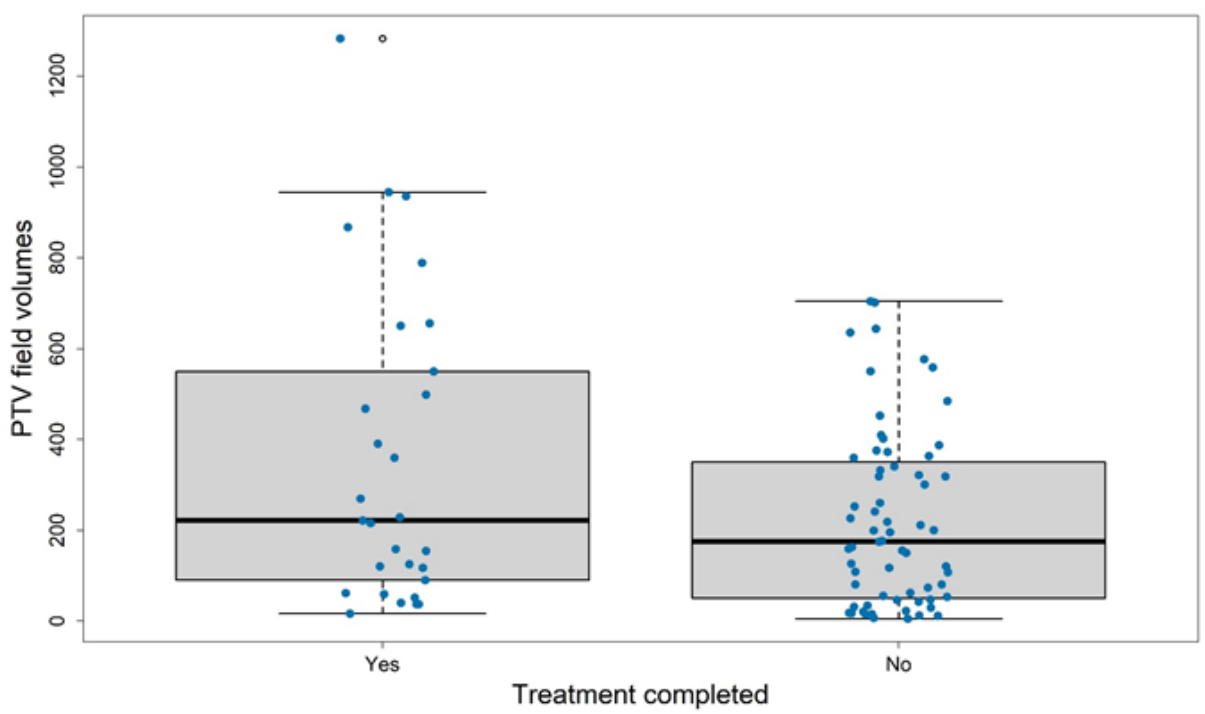

Figure 7 PTV size and completion of treatment. There was no significant difference between those who had a PTV over the median (I75 $\mathrm{cm}^{3}$ ) versus those who had a PTV under the median.

Wilcoxon rank sum test with continuity correction $\mathrm{p}$-value $=0.1058$.

Citation: Fogarty GB, Young S, Lo S, et al. Field-based radiotherapy using volumetric modulated arc therapy (VMAT) for skin field cancerisation (SFC) outcomes from I00 consecutive fields. Int J Radiol Radiat Ther. 202I;8(I):I3-24. DOI: I0.I5406/ijrrt.202I.08.00290 
Analysis for the whole cohort with keratinocytic lineage that completed treatment with radical intent $(N=64$ fields)

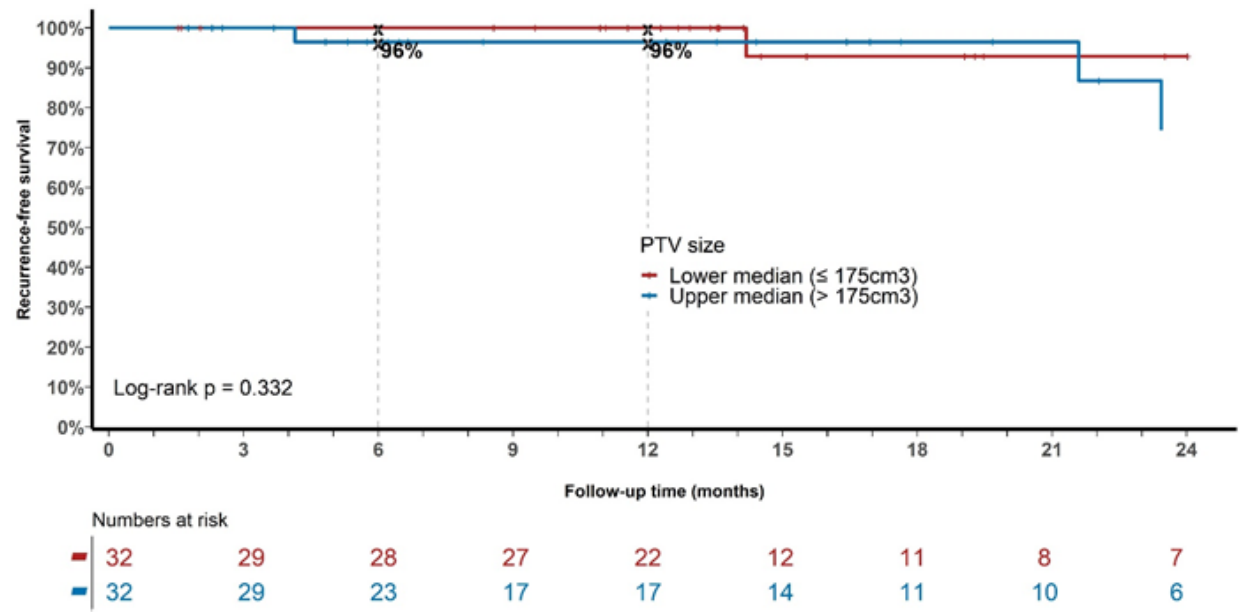

Figure 8 PTV size and recurrence. There was no significant difference between fields with a PTV over the median versus fields with a PTV under the median size.

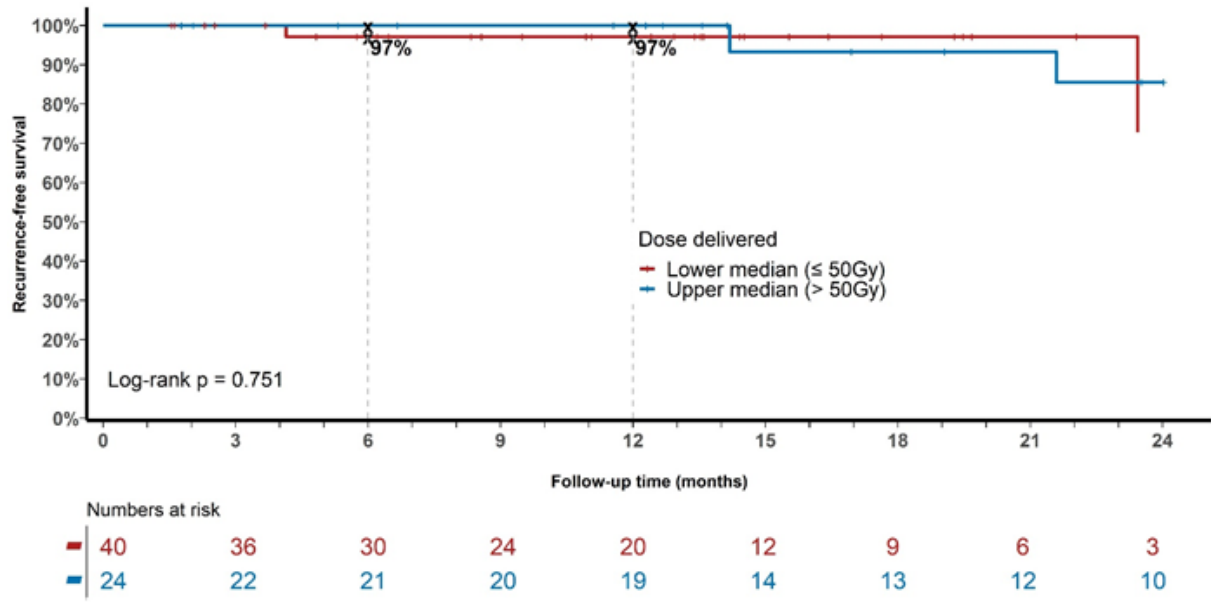

Figure 9 RT dose and recurrence. There was no significant difference between fields with an RT dose over the median versus fields with an RT dose under the median value.

Table 5 Individual patient data on the keratinocytic lineage cohort that recurred

\begin{tabular}{|c|c|c|c|c|c|c|}
\hline $\begin{array}{l}\text { Patient } \\
\text { number } \\
\text { /Field } \\
\text { number }\end{array}$ & $\begin{array}{l}\text { Age (yrs) / Sex } \\
\text { (M:F) / Immuno } \\
\text { suppressed Yes/ } \\
\text { No }\end{array}$ & $\begin{array}{l}\text { Field site/ } \\
\text { PTV size } \\
\left(\mathrm{cm}^{3}\right)\end{array}$ & $\begin{array}{l}\text { Dose prescribed } \\
\text { (Gy) / Dose given } \\
\text { (Gy) / Completed } \\
\text { Yes/No }\end{array}$ & $\begin{array}{l}\text { Type of recurrence/ } \\
\text { at months/Clinical } \\
\text { (C) or pathological } \\
\text { (P) confirmation }\end{array}$ & $\begin{array}{l}\text { Recurrence was } \\
\text { in low }(<50 G y) \\
\text { or high dose } \\
\text { area }(>50 G y)\end{array}$ & $\begin{array}{l}\text { Comment } \\
\text { RT complete } \\
\text { or stopped } \\
\text { RT due to: }\end{array}$ \\
\hline $1 / 1$ & $72 / \mathrm{M} / \mathrm{N}$ & Scalp/390 & $60 / 26 / \mathrm{N}$ & In-situ/ I4/C & Low dose & Pain \\
\hline $2 / 2$ & $76 / \mathrm{M} / \mathrm{N}$ & Leg/643 & $45 / 45 / Y$ & Invasive/23/P & Low dose & RT Complete \\
\hline $3 / 3$ & $74 / \mathrm{M} / \mathrm{N}$ & Leg/623 & $\begin{array}{l}45 / 45 / Y \\
65 \text { Gy to SIB }\end{array}$ & Invasive/I2/P & High dose (SIB) & RT Complete \\
\hline $4 / 4$ & $\begin{array}{l}\text { 84/M/Y } \\
\text { (Lupus) }\end{array}$ & $\begin{array}{l}\text { Scalp/ } \\
215\end{array}$ & $60 / 56 / \mathrm{N}$ & In-situ/6/C & High dose & Frailty \\
\hline $5 / 5$ & $81 / \mathrm{M} / \mathrm{N}$ & $\begin{array}{l}\text { Legl } \\
221\end{array}$ & $54 / 32 / N$ & In-situ/20/C & Low dose & Pain \\
\hline $5 / 6$ & $81 / \mathrm{M} / \mathrm{N}$ & $\begin{array}{l}\text { Leg2 } \\
120\end{array}$ & $54 / 32 / N$ & In-situ/20/C & Low dose & Pain \\
\hline $6 / 7$ & $8 I / M / Y-P M R$ & $\begin{array}{l}\text { Scalp } \\
158\end{array}$ & $54 / 48.6 / \mathrm{N}$ & In-situ/24/C & Low dose & $\begin{array}{l}\text { Wet } \\
\text { Desquamation }\end{array}$ \\
\hline $7 / 8$ & $82 / \mathrm{M} / \mathrm{N}$ & $\begin{array}{l}\text { LegI } \\
650\end{array}$ & $45 / 34 / \mathrm{N}$ & Invasive/I9/P & Low dose & Pain \\
\hline
\end{tabular}




\begin{tabular}{|c|c|c|c|c|c|c|}
\hline $\begin{array}{l}\text { Patient } \\
\text { number } \\
\text { /Field } \\
\text { number }\end{array}$ & $\begin{array}{l}\text { Age (yrs) / Sex } \\
\text { (M:F) / Immuno } \\
\text { suppressed Yes/ } \\
\text { No }\end{array}$ & $\begin{array}{l}\text { Field sitel } \\
\text { PTV size } \\
\left(\mathrm{cm}^{3}\right)\end{array}$ & $\begin{array}{l}\text { Dose prescribed } \\
\text { (Gy) / Dose given } \\
\text { (Gy) / Completed } \\
\text { Yes/No }\end{array}$ & $\begin{array}{l}\text { Type of recurrencel } \\
\text { at months/Clinical } \\
\text { (C) or pathological } \\
\text { (P) confirmation }\end{array}$ & $\begin{array}{l}\text { Recurrence was } \\
\text { in low }(<50 G y) \\
\text { or high dose } \\
\text { area }(>50 G y)\end{array}$ & $\begin{array}{l}\text { Comment } \\
\text { RT complete } \\
\text { or stopped } \\
\text { RT due to: }\end{array}$ \\
\hline $7 / 9$ & $82 / \mathrm{M} / \mathrm{N}$ & $\begin{array}{l}\text { Leg2 } \\
467\end{array}$ & $45 / 34 / \mathrm{N}$ & In-situ/I9/P & Low dose & Pain \\
\hline $8 / 10$ & $85 / M / N$ & $\begin{array}{l}\text { Scalp } \\
174\end{array}$ & $56 / 56 / Y$ & In-situ/ I4/C & High dose & RT Complete \\
\hline $9 / 11$ & $52 / \mathrm{M} / \mathrm{N}$ & $\begin{array}{l}\text { Leg } \\
266\end{array}$ & $45 / 45 / Y$ & In-situ/4/C & Low dose & RT Complete \\
\hline $10 / 12$ & $76 / \mathrm{M} / \mathrm{N}$ & $\begin{array}{l}\text { LegI } \\
357\end{array}$ & $45 / 18 / \mathrm{N}$ & In-situ/5/C & Low dose & Blisters \\
\hline $10 / 13$ & $76 / M / N$ & $\begin{array}{l}\text { Leg2 } \\
269\end{array}$ & $45 / 18 / \mathrm{N}$ & In-situ/5/C & Low dose & Blisters \\
\hline $11 / 14$ & $87 / M / N$ & $\begin{array}{l}\text { Leg } \\
549\end{array}$ & $45 / 39 / \mathrm{N}$ & Invasive/2/P & Low dose & Pain \\
\hline $12 / 15$ & $76 / \mathrm{M} / \mathrm{N}$ & $\begin{array}{l}\text { Scalp } \\
288\end{array}$ & $50 / 4 / \mathrm{N}$ & In-situ/2/C & Low dose & $\begin{array}{l}\text { Pt sick - } \\
\text { withdrew* }\end{array}$ \\
\hline $\begin{array}{l}\text { Ave/ } \\
\text { Totals }\end{array}$ & $\begin{array}{l}78(52-87) / \\
\text { All } \mathrm{M} / \mathrm{I} 3 \mathrm{~N}\end{array}$ & $\begin{array}{l}5 \text { Scalps; } 10 \\
\text { legs/359 }\end{array}$ & 50/3I/Y4:NII & $\begin{array}{l}10 \text { In-situ:5 } \\
\text { Invasive/20/I I C:4P }\end{array}$ & 12 Low:3Hi & $\begin{array}{l}4 \text { Complete vs } \\
\text { II Incomplete }\end{array}$ \\
\hline
\end{tabular}

Abbreviations: M; male; F, female; PTV, planning target volume; Gy, gray; SIB, simultaneous integrated boost; Ave, average; RT, radiotherapy; yrs, years; vs, versus; pt, patient; C, clinical; P, pathological

*Patient developed bowel obstruction due to unrelated causes and withdrew from RT

Table 6 Individual patient data for the fields of keratinocytic lineage that completed treatment and that had invasive disease at start of treatment

\begin{tabular}{|c|c|c|c|c|c|}
\hline Patient & Invasive component & Location & SIB & Highest dose (Gy) & Controlled at last FU \\
\hline 1 & SCC & Scalp & $\mathrm{N}$ & 55 & $Y$ \\
\hline 2 & SCC & Scalp & $Y$ & 65 & $Y$ \\
\hline 3 & SCC & Scalp & $\mathrm{N}$ & 50 & Y \\
\hline 4 & SCC & Scalp & $\mathrm{N}$ & 50 & $\mathrm{Y}$ \\
\hline 5 & $\mathrm{BCC}$ & Scalp & Y & 60 & $\mathrm{Y}$ \\
\hline 6 & SCC & Scalp & $Y$ & 60 & Y \\
\hline 7 & SCC & Scalp & $\mathrm{N}$ & 50 & $\mathrm{Y}$ \\
\hline 8 & SCC & Face & $Y$ & 55 & Y \\
\hline 9 & $\mathrm{BCC}$ & Nose & $\mathrm{Y}$ & 60 & Y \\
\hline 10 & $\mathrm{BCC}$ & Nose & $Y$ & 55 & $\mathrm{Y}$ \\
\hline II & $\mathrm{BCC}$ & Nose & $N$ & 45 & Y \\
\hline 12 & $\mathrm{BCC}$ & Nose & $N$ & 50 & $Y$ \\
\hline 13 & $\mathrm{BCC}$ & Nose & $Y$ & 55 & $Y$ \\
\hline 14 & $\mathrm{BCC}$ & Nose & $N$ & 45 & $Y$ \\
\hline 15 & $\mathrm{BCC}$ & Nose & Y & 55 & $Y$ \\
\hline 16 & $\mathrm{BCC}$ & Nose & $Y$ & 55 & $\mathrm{Y}$ \\
\hline 17 & $\mathrm{BCC}$ & Nose & $N$ & 45 & Y \\
\hline 18 & $\mathrm{BCC}$ & Nose & $N$ & 50 & $Y$ \\
\hline 19 & $\mathrm{BCC}$ & Nose & $Y$ & 55 & $Y$ \\
\hline 20 & $\mathrm{BCC}$ & Nose & $N$ & 50 & $Y$ \\
\hline 21 & SCC & Leg & $N$ & 45 & $Y$ \\
\hline 22 & SCC & Leg & $\mathrm{N}$ & 45 & $N$ \\
\hline 23 & $\mathrm{BCC}$ & Leg & $N$ & 45 & $Y$ \\
\hline Totals & $\begin{array}{l}9 \mathrm{SCC} \\
14 \mathrm{BCC}\end{array}$ & $\begin{array}{l}7 \text { Scalp } \\
\text { I Face } \\
\text { I } 2 \text { Noses } \\
3 \text { Legs }\end{array}$ & $\begin{array}{l}10 \\
Y \\
13 \\
N\end{array}$ & Ave $=52(45-65)$ & $\begin{array}{l}22 Y \\
(4 \%)\end{array}$ \\
\hline
\end{tabular}

Abbreviations: SCC, squamous cell carcinoma; BCC, basal cell carcinoma; Gy, gray; SIB, simultaneous integrated boost, Y, yes; N, no; Ave, average 
Table 7 Individual patient data on the cohort treated for melanoma and cases treated with palliative intent

\begin{tabular}{|c|c|c|c|c|c|}
\hline $\begin{array}{l}\text { Patient } \\
\text { Histology } \\
\text { Intent }\end{array}$ & $\begin{array}{l}\text { Age (yrs) / Sex } \\
\text { (M:F) / Immuno } \\
\text { suppressed Y/N }\end{array}$ & $\begin{array}{l}\text { Field site } \\
\text { / PTV size } \\
\left(\mathrm{cm}^{3}\right)\end{array}$ & $\begin{array}{l}\text { Dose prescribed (Gy)/ } \\
\text { Given }(\mathrm{Gy}) / \text { Completed } \mathrm{Y} / \mathrm{N}\end{array}$ & $\begin{array}{l}\text { Last Follow } \\
\text { up (months) }\end{array}$ & Outcome \\
\hline I LM Definitive & $75 / \mathrm{M} / \mathrm{N}$ & Nose/3 & $56 / 50.6 / \mathrm{N}$ & 15 & NED \\
\hline $\begin{array}{l}2 \\
\text { LM Definitive }\end{array}$ & $82 / \mathrm{M} / \mathrm{N}$ & Scalp/84 & $50 / 50 / Y$ & 10 & Recurrence \\
\hline $\begin{array}{l}3 \\
\text { LM Definitive }\end{array}$ & $67 / M / N$ & Nose/8 & $55 / 52.6 / \mathrm{N}$ & 8 & Recurrence \\
\hline $\begin{array}{l}4 \\
\text { LM Definitive }\end{array}$ & $7 I / M / N$ & Scalp/333 & $55 / 55 / Y$ & 12 & NED \\
\hline $\begin{array}{l}5 \\
\text { LM Definitive }\end{array}$ & $76 / \mathrm{M} / \mathrm{N}$ & Scalp/I02 & $57.2 / 54 / \mathrm{N}$ & 41 & NED \\
\hline $\begin{array}{l}6 \\
\text { MM Palliative }\end{array}$ & $97 / M / N$ & Scalp/74 & $45 / 45 / Y$ & 3 & $\begin{array}{l}\text { Persistent disease } \\
\text { but good palliation }\end{array}$ \\
\hline $\begin{array}{l}\text { MelanomaAve/ } \\
\text { Totals }\end{array}$ & $78(67-97) / M / N$ & $\begin{array}{l}4 \text { Scalp; } 2 \\
\text { Nose/I0I }\end{array}$ & $\begin{array}{l}53 / 51.2 / \\
50 \% \text { completed }\end{array}$ & 15 & $50 \%$ NED \\
\hline $\begin{array}{l}7 \\
\text { SCC } \\
\text { Palliative }\end{array}$ & $85 / M / N$ & $\begin{array}{l}\text { Scalp } \\
149\end{array}$ & $30 / 30 / Y$ & 3 & $\begin{array}{l}\text { Persistent disease } \\
\text { but good palliation }\end{array}$ \\
\hline
\end{tabular}

Abbreviations: LM, lentigo maligna;Y,Yes; N, No; F, female; M, male; NED, no evidence of disease; Gy, gray; SCC, squamous cell carcinoma; Ave, average; PTV, planning target volume

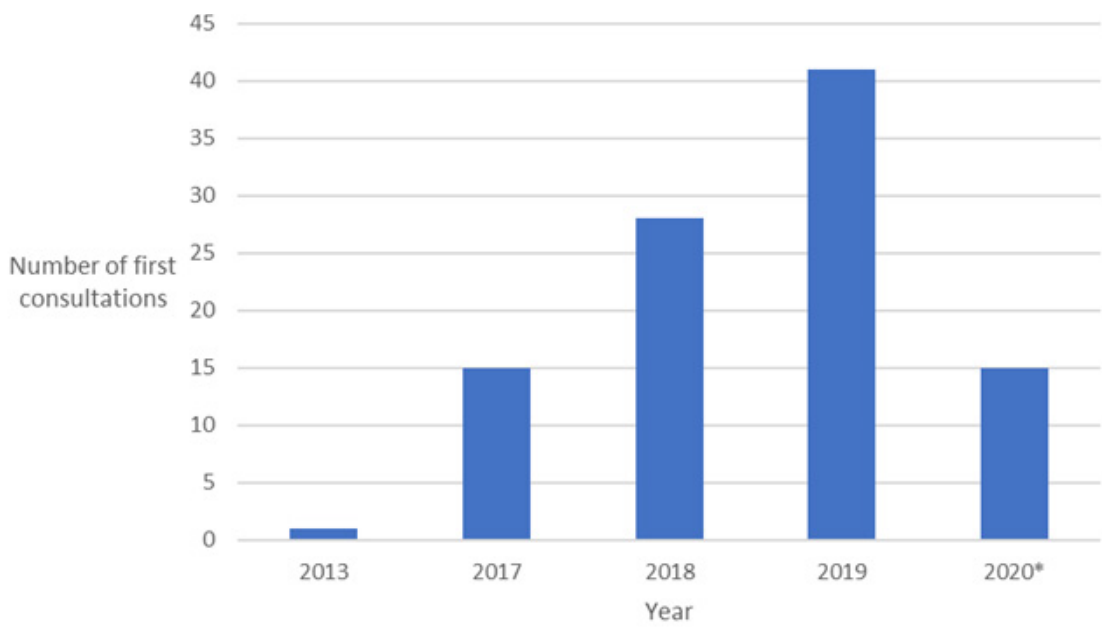

Figure 10 Number of first consultations over time.

*Consultations only counted until end of May 2020.

For first consultations: in 2013 there was one; in 2017 there were 15; in 2018 there were 28; in 2019 there were 41; and by May of 2020 there already were 15 . The rate of referrals increased over time.

\section{Discussion}

This study is a retrospective audit of the first 100 consecutive fields treated by one clinician with field-based radiotherapy using VMAT for SFC. Tables 1-3 show that the population was a mostly male (84\%) and older group with a median age of 76 years. The majority (at least $75 \%$ ) of patients had at least one previously treated SFC, and some (11\%) were immunosuppressed. Twenty percent of patients had more than one field treated with VMAT. Most keratinocytic lineage fields were either legs (27), scalps (23) or noses (20). The in-field control rate of keratinocytic lineage fields was $89 \%$ at 12 months by intention to treat.

Ninety-three fields with in-situ disease of keratinocytic lineage treated with radical intent were included in the analysis (Table 4). The average PTV size was 175 (range $5-1282$ ) $\mathrm{cm}^{3}$. The average

prescribed dose was 50 (range 15 - 72) Gy and the average delivered dose was 45 (range 4 - 72) Gy. Sixty-four (69\%) fields completed the prescribed course and there were 15 (16\%) in-field recurrences.

\section{Analysis for the whole cohort of keratinocytic lineage fields treated with radical intent $(\mathrm{N}=93)$}

Figure 2 shows a significant finding from the analysis in that the in-field control rate was $89 \%$ at 12 months. This compares favourably with the best topical treatments of $74 \% .{ }^{11}$ Jansen et al. ${ }^{11}$ study was for fields of actinic change on the head and neck involving one continuous area from a minimum of 25 to a maximum of $100 \mathrm{~cm}^{2}$, much less than the median volume of $175 \mathrm{~cm}^{3}$ in this study. Treatment failure in the Jansen et al. ${ }^{11}$ study was defined as a reduction of less than $75 \%$ in the number of actinic keratosis lesions counted at baseline. Treatment failure in our study was anything less than $100 \%$ clearance in-field. Figure 2 also shows that there was continuing recurrence out to 24 months for an in-field control rate of $69 \%$, highlighting that follow-up needs to be continued for at least this duration in this disease. In the Jansen et al. ${ }^{11}$ study, follow-up was only for 12 months. 
Figures 3 and 4 demonstrate that limb fields (legs and arms) do worse over time compared with those on the trunk (scalp, nose, face, torso; Log-rank $\mathrm{p}=0.022$ ), mainly due to increased recurrences in the legs. Early geographic miss may account for some of this as it took some time to perfect the bolus thickness and reproducibility of placement. Another issue with legs is lymphoedema. This is an acute effect that can increase the diameter of the leg and push the dermis, a blood and lymphatic rich organ, into the PTV as is discussed in Fogarty et al. ${ }^{20}$ This further creates a positive feedback loop for more swelling. ${ }^{20}$

Figure 5 shows that immunosuppression $(n=9 ; 10 \%)$ was not associated with an increased rate of recurrence in this small cohort (Log-rank $\mathrm{p}=0.225$ ). This is not consistent with invasive disease which tends to recur more often in the immunosuppressed after definitive treatment. ${ }^{21}$ This suggests that in-situ and invasive disease of keratinocytic lineage may have different radiobiologies.

Figure 6 shows that recurrence over time for the whole cohort with keratinocytic lineage treated with radical intent is higher in those who did not complete the prescribed treatment as compared to those who did. In-field control for those who completed the prescribed treatment at 12 months was $98 \%$ as compared with $71 \%$ for those who did not $(\log -$ rank $p<.0001)$. This suggests that delivery of the prescribed treatment is important. Clinicians treating this disease found, that a treatment break of at least two weeks after the first 10 -12 daily fractions were delivered, decreased acute side effects and enabled a higher rate of treatment completion. After this first phase, there are usually no side effects. Sometimes further breaks are needed to complete RT. The break does not appear to affect the recurrence rate. Continuing RT until acute effects developed usually led to patients abandoning treatment completely resulting in a greater risk of recurrence due to undertreatment. Decreased dose is associated with higher rates of recurrence in this study. We eagerly await the outcome of the currently accruing trial, GenesisCare Epithelial Neoplasia Trial using Lighter dose Extensive field Radiotherapy (The GENTLER Trial; Trial registry number: ACTRN12620000618954p ${ }^{22}$ to see if this is a real effect. This trial is examining the durability of in-field control with 30 Gy over five weeks in patients with ESFC unable to tolerate the national protocol dose of 45-50 Gy.

Figure 7 describes the impact of PTV size on completion of treatment. In this analysis, there was no significant difference in prescription completion between those who had a PTV over the median $\left(175 \mathrm{~cm}^{3}\right)$ versus those who had a PTV under the median. Wong et $\mathrm{al}^{18}$ in their seminal work suggested that treatment completion was more likely with a PTV of less than $800 \mathrm{~cm}^{3}$. This study only had three fields over $800 \mathrm{~cm}^{3}$ : one leg of $935 \mathrm{~cm}^{3}$, another leg of $944 \mathrm{~cm}^{3}$ and a back of $1280 \mathrm{~cm}^{3}$. None of these fields completed treatment, but patients were still in remission at last follow-up of 17, 17 and 20 months, respectively.

\section{Analysis for the whole cohort with keratinocytic lineage who completed treatment with radical intent ( $N=64$ fields)}

Volume, total dose and dose per fraction are essential fundamental radiation variables for disease control. The most important variable is volume because, if the volume is right and the dose is inadequate, at least some of the target receives dose. However, if the volume is not accurate, no matter how correct the dose is, it is going to the wrong volume, and so there is a geographic miss- the bane of RT. Radiation oncologists (ROs) are charged with ensuring the volume is correct through proper contouring and supervising on-going quality of treatment delivery. VMAT is an advantage to ROs as it can treat a thin convex shaped target of ESFC with excellent conformality and homogeneity of dose and rapid fall off. Dose is not dumped deep within skin which can cause lymphoedema. ${ }^{14}$ Dose per fraction is limited to 2 Gy or less due to the amount of normal tissue in the PTV that must repair between fractions. It is therefore fixed for treatment with radical intent. Volume and total dose were therefore analysed in this cohort.

Figure 8 shows that there was no significant association between recurrence and PTV size (Log-rank $\mathrm{p}=0.332$ ). Intuitively, one might think that the larger the size of the field, the greater the chance poor conformality and inhomogeneity of dose, and therefore increased risk of recurrence. This phenomenon is reflected for invasive cancer in the T stage of TNM staging. ${ }^{23}$ This favourable result may mean that the in-situ bearing volume was consistently completely enclosed by the PTV, reflecting that the right target was identified in our protocol, and correctly contoured in this cohort. It also reflects high-quality planning and treatment delivery by RT staff.

Figure 9 shows that there was no significant difference between fields with an RT dose over the median value of 50Gy versus those with an RT dose under the median in terms of in-field control (Logrank $p=0.751)$. This suggests that the RT dose in our national protocol is enough to control disease and adds some justification to the de-escalation of dose for in-situ disease arising from skin as compared to other tissues like mucosa. It has been a challenge for ROs to accept that 45-50 Gy in 25 fractions with at least a two-week break is enough to control in-situ skin disease of keratinocytic lineage. Usually other squamous malignancies need doses over $60 \mathrm{~Gy}$, and a break in treatment has been shown in randomised controlled trials (RCT) to be detrimental. ${ }^{24}$

\section{Individual patient data on the cohort that recurred (Table 5)}

Table 5 displays individual patient data on the keratinocytic lineage cohort that experienced recurrence. For the 12 patients, the average age was 78 (range 52 - 87), all were male, and none were immunosuppressed. For the fields, the average PTV was $359 \mathrm{~cm}^{3}$, average prescribed dose was $50 \mathrm{~Gy}$, and the average delivered dose was $31 \mathrm{~Gy}$. Four patients completed treatment but 11 did not. There were 10 recurrences of in-situ and five of invasive disease at an average of 20 months. Of these, 11 were diagnosed clinically and four were reported pathologically following biopsy. Twelve occurred in a low dose region and three in a high dose region given a simultaneous integrated boost (SIB). Recurrences were therefore mostly true infield recurrences in the in-situ areas and not in a SIB area (Figure 11).

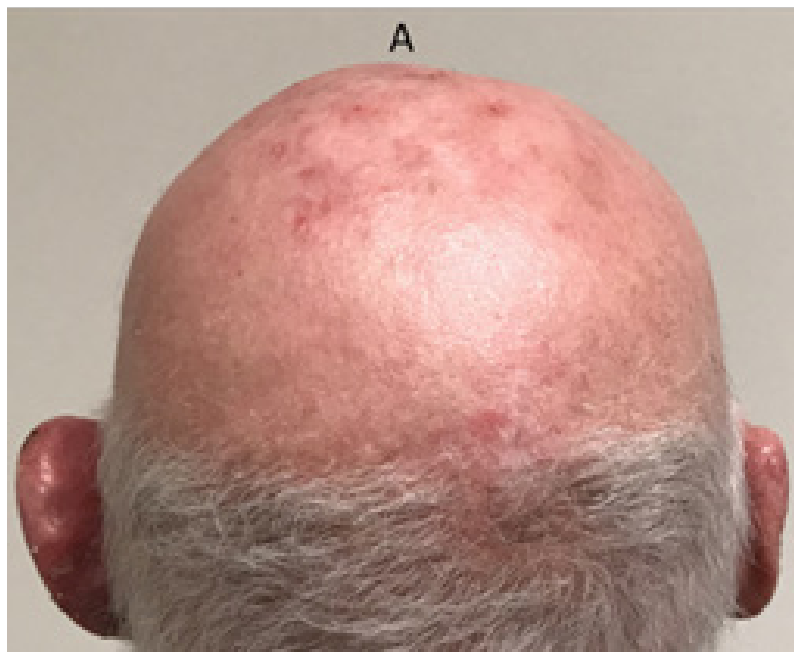




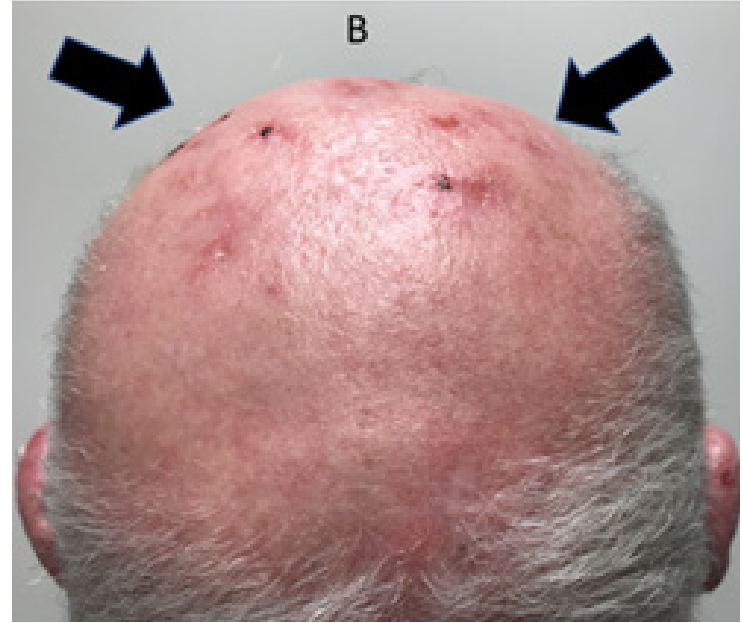

Figure I I This 79-year old immunocompetent male was planned for $60 \mathrm{~Gy}$ in 30 fractions with no planned break via VMAT to the scalp for ESFC.At I8 Gy he developed erythema with heat within the scalp, making him uncomfortable. He finally declined any further RT at 26 Gy due to pain requiring narcotic analgesia. The scalp healed in two weeks.

Figure I IA Three months post RT showing continuing complete response in the scalp.

Figure I I B Five months post RT scalp showing true in-field recurrence in the in-situ areas (black arrows).

Recurrences occurred in 5 out of $23(22 \%)$ scalps. Only one scalp with recurrence completed the prescribed RT $(20 \%)$. This is despite scalps having a higher median dose compared with fields from any other anatomical location. The higher dose to scalps is because the national skin program started with scalps. As more scalps were part of the dose-finding cohort, a higher dose, even to $60 \mathrm{~Gy}$ as per in-situ disease in other tissues, was prescribed. ${ }^{25,26}$ Recurrences occurred in 10 out of 27 (37\%) legs. Only three legs with recurrences completed the prescribed RT (30\%). The reason for not finishing RT was due to acute effects consisting of mainly swelling in the legs associated with pain. One patient had two legs treated with no reaction at the end of the first phase of 18 Gy in 10 fractions, but after a two-week break with no further treatment, significant painful blistering was observed (Figure 12) and further treatment was cancelled.

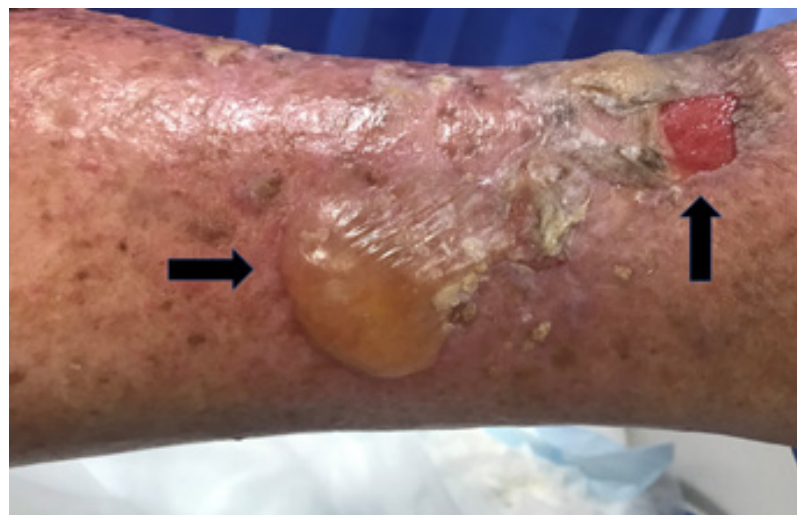

Figure 12 Significant painful blistering medial left ankle at the end of a two-week break following $18 \mathrm{~Gy}$ in 10 fractions. Horizontal arrow shows an unpopped blister.Vertical arrow shows a popped blister.This phenomenon was presumably due to lymphoedema.

These findings of recurrence in the scalp and legs are consistent with Figure 6 in that the biggest risk for recurrence was noncompletion of the prescribed treatment.
Table 6 shows individual patient data for fields of keratinocytic lineage that completed treatment and had invasive disease at start of treatment. Of 23 fields, 9 had SCC and 14 had BCC. Field locations were 7 scalp, 1 face, 12 noses and 3 legs. Ten had SIB for these invasive lesions while 13 did not. The average highest dose was 52 (range: 45 - 65) Gy, and 22 were controlled at last follow-up, while $1(4 \%)$ was not. Invasive disease seemed to not need a SIB in some cases. This further reflects the increased radiosensitivity of invasive disease of keratinocytic lineage..$^{27}$ This lends weight to the approach taken by some ROs in dealing with invasive disease within the field. Their approach is to treat the whole field, including the in-field invasive components, to adjust the dose needed for fields. They then review patients at six weeks post RT and add an immediate boost at that time to any remaining invasive disease. This often means a smaller boost volume as there has normally been some shrinkage of the invasive disease, reminiscent of the adaptive split course for locally advanced skin cancer of keratinocytic lineage. ${ }^{28}$ In some cases, the invasive component has had a complete response and the boost is not needed. ${ }^{29}$

Table 7 shows individual patient data on the cohort treated for melanoma and cases treated with palliative intent. Of the six melanoma cases, five had lentigo maligna (LM), the average age was 78 years (range: $67-97$ years), all were male, four were scalps and two were noses. The average PTV size was $101 \mathrm{~cm}^{3}$. The average dose prescribed was $53 \mathrm{~Gy}$ and the average delivered dose was $51.2 \mathrm{~Gy}$. Fifty percent of patients completed the prescribed dose and two of the five radically treated fields recurred by the average time of followup at 15 months. Patient number 4 was the first to be treated with VMAT for ESFC due to LM. He died of an unrelated illness with in-field control at 41 months,.${ }^{14}$ As described elsewhere, it seems that melanoma in-situ disease still needs dose and is not as radiosensitive as in-situ disease of keratinocytic lineage. ${ }^{26}$ Good palliation was achieved in the two cases palliatively treated.

This study has provided key learnings and suggests that further research is warranted. It seems that if the dose used in our national protocol is totally delivered there is sufficient in-field control of fields of in-situ disease from keratinocytic lineage regardless of treatment breaks. Completing the prescribed course is important. Anything that can be done to assist this, including more breaks, should be done. Identifying those at risk of lymphoedema is the subject of a study being undertaken by Dr Chelsie O'Connor and the Australian Lymphoedema Education, Research and Treatment team at Macquarie University Hospital. ${ }^{30}$

In-situ disease of keratinocytic lineage appears radiosensitive and sometimes dramatically so. What is needed is a good radiobiological study to find a marker to help tailor the dose to individuals. This has eluded discovery to date. This may be related to genetic issues such as increased tumour mutation load ${ }^{31}$ due to UV exposure, or variations in manganese - a radiation scavenger in tissue. ${ }^{32}$ Skin cancer seems the ideal organ to study with markers in mind as it is easy to observe and accurately biopsy. Other lessons from this study showed that unplanned breaks and discontinuation of therapy were primarily due to acute toxicity. There were two instances when this was not the case: one patient declined further RT due to personal reasons and another (patient 12 in Table 5), withdrew as he developed an unrelated bowel obstruction.

The rate of referrals increased quickly over time compared with referrals for RT for other indications within this practice. ${ }^{33}$ This reflects the need for a solution to ESFC. This series also provided an opportunity to learn about unexpected phenomena occurring with VMAT in ESFC. These include uncommon keratoacanthomas ${ }^{34}$ and 
even more uncommon hair re-pigmentation, ${ }^{35}$ both arising in the penumbral areas. VMAT does result in a penumbra which is larger than other RT modalities used in skin, and the side effects that may result need to be accounted for at the treatment consent stage.

This study has significant limitations. The data was retrospectively collected. The sample size is from only one clinician and is small. Multiple histologies and anatomical locations are included. Patients were not treated consistently as the national protocol was evolving during the timeframe. Hopefully, the information gained from this study will serve as a template for ongoing research and treatment of this common condition.

\section{Conflicts of interest}

The authors have no conflicts of interest to declare.

\section{Acknowledgments}

The authors wish to thank Aileen Eiszele of A\&L Medical Communications for editing, writing assistance and manuscript preparation. They also wish to thank the radiation therapy, physics and nursing teams at the GenesisCare centres where this research was carried out together with the patients who contributed. The clinician involved would also like to thank the Queensland peer review team for their guidance in this population cohort. Thanks also to David Tighe for constructing Figure 10. Finally, the authors wish to acknowledge Mark Buscombe for his support towards the publication of this article.

\section{References}

1. Green AC. Epidemiology of actinic keratoses. Curr Probl Dermatol. 2015;46:1-7

2. Menzies SW, Liyanarachchi S, Coates E, et al. Estimated risk of progression of lentigo maligna to lentigo maligna melanoma. Melanoma Res. 2020;30(2):193-197.

3. Figueras Nart I, Cerio R, Dirschka T, et al. Defining the actinic keratosis field: a literature review and discussion. $J$ Eur Acad Dermatol Venereol. 2018;32(4):544-563.

4. Hofbauer G, Anliker M, Boehncke WH, et al. Swiss clinical practice guidelines on field cancerization of the skin. Swiss Med Wkly. 2014;144:w14026

5. Pandeya N, Olsen CM, Whiteman DC. The incidence and multiplicity rates of keratinocyte cancers in Australia. Med J Aust. 2017;207(8):339343.

6. Iannacone MR, Sinnya S, Pandeya N, et al. Prevalence of skin cancer and related skin tumors in high-risk kidney and liver transplant recipients in Queensland, Australia. J Invest Dermatol. 2016;136(7):1382-1386.

7. Staples MP, Elwood M, Burton RC, et al. Non-melanoma skin cancer in Australia: the 2002 national survey and trends since 1985. Med J Aust. 2006; $184: 6-10$

8. Fogarty GB, Christie D, Spelman LJ, et al. Can modern radiotherapy be used for extensive skin field cancerisation: An update on current treatment options. Biomed J Sci \&Tech Res. 2018;4(1):BJSTR.MS.ID.000998.

9. Gupta AK, Paquet M, Villanueva E, et al. Interventions for actinic keratoses. Cochrane Database Syst Rev. 2012;12:CD004415.

10. Sinclair R, Baker C, Spelman L, et al. A review of actinic keratosis, skin field cancerisation and the efficacy of topical therapies. Australas $J$ Dermatol. 2020;PMID:32840870.

11. Jansen MHE, Kessels JPHM, Nelemans PJ, et al. Randomized trial of four treatment approaches for actinic keratosis. $N$ Engl $J$ Med. 2019;380(10):935-946.
12. Perera E, Gnaneswaran N, Staines C, et al. Incidence and prevalence of non-melanoma skin cancer in Australia: A systematic review. Australas $J$ Dermatol. 2015;56(4):258-267.

13. Australian Institute of Health and Welfare \& Cancer Australia 2008. Nonmelanoma skin cancer: general practice consultations, hospitalisation and mortality. Cancer series no. 43. Cat. no. CAN 39. Canberra: AIHW.

14. Daniel Santos E, Green JA, Bhandari N, et al. Tangential volumetric modulated radiotherapy-A new technique for large scalp lesions with a case study in lentigo maligna. Int J Bioautomation. 2015;19(2);223-236.

15. Martin TD, Moutrie Z, Tighe D, et al. Volumetric modulated arc therapy (VMAT) for skin field cancerisation of the nose - A technique and case report. Int J Radiol Radiat Ther. 2018;5(3):142-148.

16. Fogarty GB, Christie DRH, Kaminski A, et al. A radiation oncology approach for using definitive radiotherapy with volumetric modulated arc therapy (VMAT) for skin field cancerisation (SFC). Int $J$ Radiol Radiat Ther. 2018;5(4):227-234.

17. Potter A, Price M, Papworth D, et al. A technique for treating extended skin field cancerisation using volumetric modulated arc therapy. Int $J$ Radiol Radiat Ther. 2019;6(4):111-119.

18. Wong B, Christie D, Hellyer J, et al. Volumetric modulated arc therapy (VMAT) for extensive skin field cancerisation (ESFC) - exploring the limits of treatment volumes with a case series of backs. Int $J$ Radiol Radiat Ther. 2020;7(6):184-192.

19. Burnet NG, Thomas SJ, Burton KE et al. Defining the tumour and target volumes for radiotherapy. Cancer Imaging. 2004;4(2):153-161.

20. Fogarty GB, Christie D, Potter A. Volumetric modulated arc therapy (VMAT) for extended skin field cancerisation (ESFC): Radiobiological learnings from unique patient cases. Int $J$ Radiol Radiat Ther. 2019;6(5):156-162.

21. Khan L, Breen D, Zhang L, et al. Predictors of recurrence after radiotherapy for non-melanoma skin cancer. Curr Oncol. 2014;21(2):e326-e329.

22. The GENTLER Trial; Trial registry number: ACTRN12620000618954p. Accessed 25/03/21.

23. Brierley JD, Gospodarowicz MK, Wittekind C. TNM Classification of Malignant Tumours. Eighth Edition, Wiley Press. 2018.

24. Beitler JJ, Zhang Q, Fu KK, et al. Final results of local-regional control and late toxicity of RTOG 9003: A randomized trial of altered fractionation radiation for locally advanced head and neck cancer. Int $J$ Radiat Oncol Biol Phys. 2014;89(1):13-20.

25. Moran MS, Zhao Y, Ma S, et al. Association of radiotherapy boost for ductal carcinoma in situ with local control after whole-breast radiotherapy. JAMA Oncol. 2017;3(8):1060-1068.

26. Fogarty GB, Hong AM, Rocha L et al. Is more dose and skin reaction required when treating early lentigo maligna definitively with radiotherapy? A case series. Int J Radiol Radiat Ther. 2020;7(5):142-145.

27. Gunaratne DA, Veness MJ. Efficacy of hypofractionated radiotherapy in patients with non-melanoma skin cancer: Results of a systematic review. J Med Imaging Radiat Oncol. 2018;62(3):401-411.

28. Fogarty GB, McLaren KR, Moutrie Z, et al. Locally advanced skin cancers of the frail and elderly - consider adaptive split course radiotherapy (ASCRT). Br J Dermatol. 2018;179(6):1416-1417.

29. Personal communication with Dr Sid Baxi, radiation oncologist, GenesisCare, Queensland, Australia.

30. Personal communication with Dr Chelsie O'Connor, radiation oncologist, GenesisCare, New South Wales, Australia.

31. Chalmers ZR, Connelly CF, Fabrizio D et al. Analysis of 100,000 human cancer genomes reveals the landscape of tumor mutational burden. Genome Med. 2017;9(1):34. 
32. Doble PA, Miklos GLG. Distributions of manganese in diverse human cancers provide insights into tumour radioresistance. Metallomics. 2018;10(9):1191-1210.

33. Tighe DG, Karle B, Hollands A, et al. Definitive radiotherapy for basal cell carcinoma and cutaneous squamous cell carcinoma of the nose. $J$ Dermatol Res. 2019;13;4(1):156-162.
34. Mullin SJ, Lochhead A, Haddad R, et al. Keratoacanthomas following definitive volumetric modulated arc radiotherapy for skin field cancerization. Int J Radiol Radiat Ther. 2019;6(6):225-232.

35. Prasad S, Dougheney N, Hong A, et al. Scalp hair repigmentation in the penumbral region of radiotherapy-a case series. Int J Radiol Radiat Ther. 2020;7(5):151-157. 